extinctions, suspect terrains or orbital cycles as a cause of ice ages. The principal shortcoming is that the book is written at a very elementary level and has a minimal bibliography. There is little critical evaluation or in-depth treatment of specific subjects, and detailed examples are taken almost exclusively from the United States. This is essentially an Earth history digest aimed at the large American freshman and sophomore market; in consequence, it is unlikely to be adopted widely for geology honours courses in British universities, where world history is normally dealt with at a comparatively advanced level after a thorough grounding in stratigraphic principles has been undertaken with reference to local examples.

For the past eight years the most suitable textbook for senior undergraduates has been Windley's The Evolving Continents, in which a pioneering attempt was made at an overview of continental evolution from the Archaean onward, within a conceptual framework of plate tectonics. Windley's book has been a well warranted success and the second edition is timely.

So rapid have been the advances of recent years that substantial revision has proved necessary, though the basic outline remains unchanged. The new Harland timescale is adopted uncritically in a new opening chapter. It is perhaps as well that Windley did not wait a further couple of years before revision, because he would then have had three other new timescales to contend with, all differing in some important respects. Besides major changes in the Precambrian chapters there are new sections for the Phanerozoic on a host of subjects. These include, among many others, phosphorites in relation to oceanic upwelling, mass extinctions, the Iapetus Ocean, the elevation and climate of Pangaea, oceanic mineralization, Pacific island arcs, suspect terrains and the structure and evolution of the Himalayas. The bibliography remains at 30 pages but the contents are much changed.

As in the first edition, Windley is at his most authoritative when dealing with tectonics, especially the Archaean and Proterozoic, though he is not sufficiently up to date to record that much of eastern Asia is now thought to consist of isolated continental fragments brought together since the late Palaeozoic. On subjects such as palaeoenvironments, or those dealing with events in the biosphere, he is less comprehensive and reliable. The big advances recently in the understanding of sedimentary basin formation and continental margin subsidence are largely ignored, and Phanerozoic sea-level changes receive only a scant treatment. It would, however, need a superman to produce an advanced textbook of Earth history that was equally strong in all fields.

\section{Student pollution}

Peter S. Liss

Fundamentals of Air Pollution, 2nd Edn.

By Arthur C. Stern et al.

Academic: 1984. Pp.530. \$39.50, £28.

Pollution of our Atmosphere.

By B. Henderson-Sellers.

Adam Hilger: 1984. Pp.210. Hbk £30,

$\$ 49 ; p b k$ £13.95, $\$ 23$.

AIR POLLUTION is a fast-moving topic which has attracted much public attention in recent years. Developments in it have often been haphazard since, instead of a steady flow of funding for research, there has been a tendency to throw large amounts of money at particular problems, for example acid rain, and halocarbons and their possible impact on stratospheric ozone. With this sort of patchy temporal progress it might be thought that there would be widespread disagreement as to what should be included in the corpus of knowledge constituting the subject. However, to judge from these two books there is apparently considerable unanimity as to what courses in air pollution in higher education should contain. Basically both of them deal with sources, effects, measurement, monitoring, meteorology, and regulatory and engineering control of air pollution. But there the similarity ends.

The book by Stern et al. is a new edition of a publication of the same title which appeared 11 years ago. Two of the original four authors remain and two new ones have been recruited. The style and level of the new edition are much as previously, but the text has not merely been revised and considerable parts of it are completely new. Even so, there is a less than modern air about it, a possible reason for which will be discussed shortly. Students will find the book packed with information and it will serve them not only while they are at college but also in any subsequent career concerned with atmospheric science.

Henderson-Sellers's book is definitely a new production but again it doesn't strike me as really being at the forefront of knowledge. It is readable and a real attempt is made to explain how physical processes operate in the atmosphere, rather than merely stating that they do, as is done in less didactic treatments. The book is quite short and students should find it a good read, though I'm not sure it will be as useful to them after graduation as will Stern et al.

My principal grouse about both books is their lack of treatment of atmospheric chemistry. Both attempt to deal with chemical aspects of the subject but the approach is peripheral rather than central. Of the two, Stern et al. does a better job in this regard but even here the chemistry has insufficient weight. Because of this, important topics such as removal of air pollutants by natural cleansing processes, hydroxyl chemistry, and even acid rain receive only scant attention. It is the underplaying of chemical aspects which 1 believe gives both books a somewhat dated air. Arguably the biggest growth area in air pollution research in the past decade has been in atmospheric chemistry. Books in which insufficient attention is paid to this will inevitably look old before their time.

Peter S. Liss is Reader in the School of Environmental Sciences at the University of East Anglia.

\section{Archaeology anew}

\section{Colin Renfrew}

\section{Prehistoric Europe.}

By Timothy Champion, Clive Gamble, Stephen Shennan and Alasdair Whittle. Academic: 1984. Pp.359. Hbk \$45, f28.50; pbk \$23.50, f14.50.

WHEN a discipline has recently undergone a profound, perhaps revolutionary transformation, the first textbook to follow that upheaval is of more than usual significance. The study of European prehistory has indeed undergone such a transformation over the past 15 years, with the widespread acceptance of a chronological system very different from that which prevailed earlier, and with the development of interests and forms of explanation which were not much in evidence then. This ambitious volume offers the first reasonably comprehensive overall coverage of the resulting subject, from the palaeolithic period to the iron age.
Three qualities separate the prehistoric archaeology of today from the traditional version, seen in a series of standard works from V. Gordon Childe's Dawn of European Civilisation (first edition 1925) to Stuart Piggott's Ancient Europe (1965). The first is the happy lack of preoccupation with chronology: radiocarbon dating has now successfully solved many of the outstanding chronological problems. So that while the early works of the new radiocarbon era were backed up by bulky appendices of date lists, much needed at the time, these are absent here. A second feature is the refreshing absence of automatic diffusionist assumptions: no longer is it taken as self-evident (whether by explicit axiom or by unstated convention) that most changes in the prehistoric record came about as the result of contacts with the civilized lands of the Near East by a process of the "diffusion" of culture. And thirdly, the processual approach now predominates: that is to say the emphasis is on the explanation of change through an analysis of economic conditions and social structures. The discussions of change in 